\title{
MOBILE PHONE RADIATION SIMULATOR COULD BE USED FOR TESTING THE EFFECTS OF MICROWAVES ON BIOLOGICAL SYSTEMS
}

Milorad Milošev ${ }^{1}$, Milan Novaković ${ }^{1}$

${ }^{1}$ The Medical Faculty University of Kragujevac

\author{
SIMULATOR ZRAČENJA MOBILNOG TELEFONA MOŽE SE KORISTITI \\ ZA ISPITIVANJE UTICAJA MIKROTALASA NA \\ BIOLOŠKE SISTEME \\ Milorad Milošev ${ }^{1}$, Milan Novaković \\ ${ }^{1}$ Medicinski fakultet Kragujevac
}

A question that has repeatedly drawn the attention in recent years not only of the scientific community, but also of the general public is the potentially harmful effect of mobile phones on users' health. This concern especially applies to long-term use and use by children (1). It is necessary to perform a large number of studies because the effects microwave radiation from cell phones have on human organisms are still unclear $(2,3,4)$. To understand the mechanisms of action of microwave radiation from mobile phones on biological systems, a simulator of mobile phone radiation (SZMT-QUAD 2010) was created. This simulator is actually a computer-controlled mobile phone (Figure 1A).

SZMT-QUAD 2010 was purchased from the manufacturer: the Innovation Center of Belgrade's Faculty of Electrical Engineering Ltd. (ICEF) 11120 Belgrade, 73 Boulevard of King Aleksandar. It was constructed by Dipl. Ing. Nikola Rajovic. The characteristics of the SZMT-QUAD 2010 radiation correspond to the characteristics of the original mobile phone working on the GSM-900 MHz (Global System for Mobile communications: originally from Groupe Spécial Mobile),
GSM-1800 MHz and DCS-1800 MHz (Digital Cellular System $1800 \mathrm{MHz}$ ) frequencies. The antenna of SZMT-QUAD 2010 is located in the box and fully corresponds to the frequency bands of GSM-900 MHz, GSM-1800 MHz and DCS$1800 \mathrm{MHz}$ GSM by power and radiation bands.

Adhesive foil marking the field of radiation of the SZMT-QUAD 2010 antenna was affixed on the cover of the box to mark the areas where the testing samples were placed (Figure 1B). For each batch of samples irradiated, the amount of energy radiated was calculated through the signal, which was automatically depicted on the computer monitor and expressed in $\mathrm{dBm}$.

SZMT-QUAD 2010 consists of the following parts: box, power supply, circuit board, GSM module, antenna, GSM module control button, light indicators, and PC software (Figure 1B).

The GSM module is used to provide registration, identification and voice communication over the GSM network. The functionality of the module is independent of the chosen network provider.
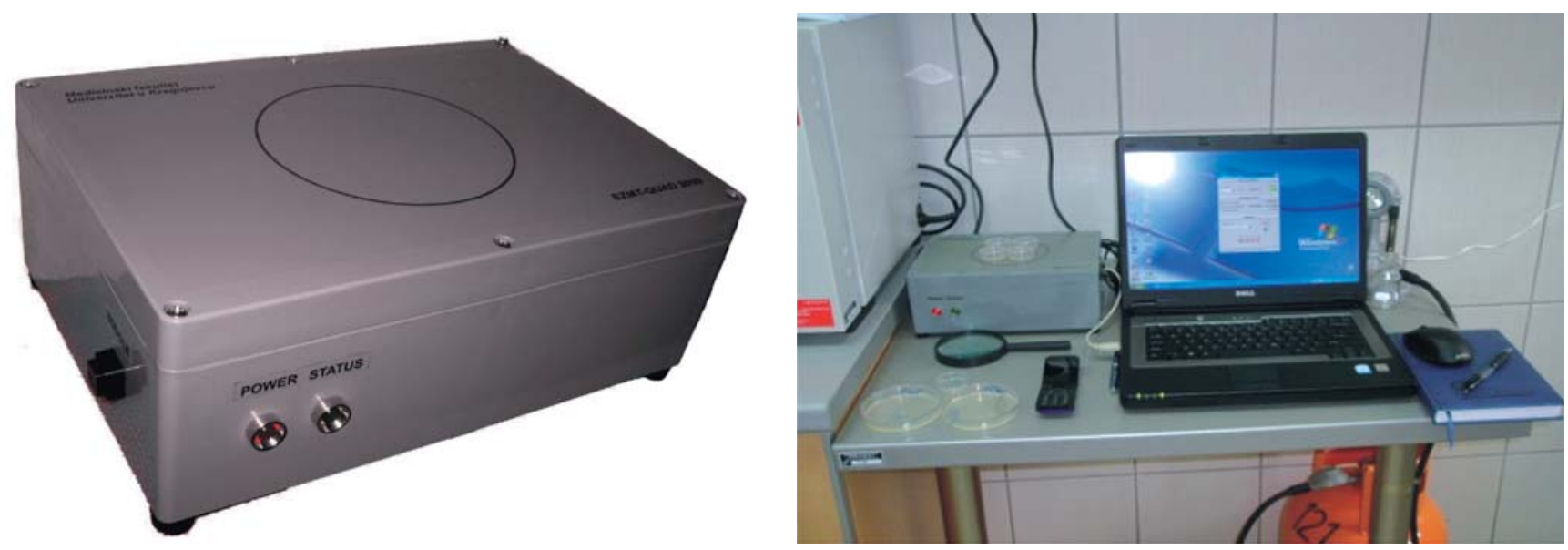

Figures 1A and B. SZMT- QUAD 2010 
A special software application called "Radiation Simulator" was developed for Microsoft Windows to manage SZMT-QUAD 2010.

The application has the following functionalities:

- Checking the SZMT - QUAD 2010 registration with the network provider

- identifying the service provider and frequency range

- continuously presenting the signal strength from the base station of the network operator

- selecting the type of work - sleep or conversation

- measuring the duration of each type of simulation

These qualities make the SZMT-QUAD 2010 simulator a useful piece of equipment for testing the biological effects of microwave radiation from mobile phones. We used the simulator to test the effect of microwave radiation on the growth of bacterial cultures in vitro. SZMT-QUAD 2010 should be increasingly used in various experimental preclinical models to broaden our knowledge about the potentially harmful effects of microwave radiation from mobile phones.

\section{ACKNOWLEDGMENTS}

The authors would like to express their gratitude to the Medical Faculty University of Kragujevac for the Junior Internal Research Grant number 10/10, by which the SZMT-QUAD 2010 simulator was purchased.

\section{REFERENCES:}

1. Krstić D, Đinđić B, Kocić G, Petković D, Radić S, Sokolović D. The harmful effects of electromagnetic field of $50 \mathrm{~Hz}$ frequency to biological systems. Acta Medica Medianae 2003; 42: 7-14.

2. Salford GL, Brun EA, Eberhardt LJ, Malmgren L, Bertil R, Persson R. Nerve Cell Damage in Mammalian Brain after Exposure to Microwaves from GSM Mobile Phones. Environmental Health Perspectives 2003; 111: 881-3.

3. Kundi M. The controversy about a possible relationship between mobile phone use and cancer. Env Health Perspectives 2009; 117: 316-24.

4. Hardell L, Sage C. Biological effects from electromagnetic field exposure and public exposure standards. Biomedicine \& Pharmacotherapy 2008; 62: 104-9. 